\title{
Group I Metabotropic Glutamate Receptors at GABAergic Synapses in Monkeys
}

\author{
Jesse E. Hanson and Yoland Smith \\ Division of Neuroscience, Yerkes Regional Primate Research Center and Department of Neurology, Emory University, \\ Atlanta, Georgia 30329
}

Recent data showed that group I metabotropic glutamate receptors (mGluRs) are located perisynaptic to the postsynaptic specializations of asymmetric glutamatergic synapses in the cerebellum and hippocampus in rats. In the present study, we used immunogold labeling to elucidate the subsynaptic localization of group I mGluRs (mGluR1a and mGluR5) in the internal and external segments of the globus pallidus in monkeys. In contrast to hippocampal and cerebellar neurons, which receive massive glutamatergic inputs, dendrites of pallidal neurons are covered with GABAergic boutons from the striatum intermingled with a small proportion of glutamatergic terminals arising largely from the subthalamic nucleus. In line with previous data,
mGluR1a and mGluR5 immunoreactivity was found at the edge of the postsynaptic specializations of asymmetric synapses established by subthalamic-like boutons in the monkey pallidum. However, a large proportion of gold particles were also seen in the main body of the postsynaptic specializations of symmetric synapses formed by striatal GABAergic terminals. These data raise questions about the possible sources of activation of these receptors and the potential roles of group I mGluRs in modulating GABAergic neurotransmission at striatopallidal synapses.

Key words: globus pallidus; striatum; immunogold method; subthalamic nucleus; metabotropic glutamate receptor; mGluR
Glutamate, the major excitatory neurotransmitter in the CNS, activates both ionotropic and metabotropic receptors. Ionotropic receptors are ion channels that mediate fast changes in the postsynaptic membrane potential, whereas metabotropic receptors are coupled to G-proteins and initiate intracellular signaling cascades. To date, eight different subtypes of metabotropic glutamate receptors (mGluRs) have been identified and termed mGluR1 through mGluR8. These different subtypes have been divided into three groups based on their sequence homology, transduction mechanisms, and pharmacological profiles (Nakanishi, 1994; Conn and Pin, 1997). The focus of the present study is the group I mGluRs, which include the splice variants of mGluR1 (mGluR1a, mGluR1b, mGluR1c, and mGluR1d) and mGluR5 (mGluR5a and mGluR5b). Activation of these receptors stimulates phospholipase $\mathrm{C}$ and phosphoinositide hydrolysis. Evidence exists for a variety of effects mediated by group I mGluRs, many involving modulation of ion channels resulting in changes in membrane excitability (Nakanishi, 1994; Pin and Duvoisin, 1995; Conn and Pin, 1997).

Light microscopic immunocytochemistry and in situ hybridization studies have shown that group I mGluRs are strongly expressed in various populations of neurons in the rat basal ganglia (Martin et al., 1992; Testa et al., 1994, 1998; Petralia et al., 1997; Berthele et al., 1998), but very little is known about their synaptic localization in these brain structures. However, the synaptic localization of mGluRs has been examined in the rat hippocampus

\footnotetext{
Received April 5, 1999; revised May 13, 1999; accepted May 17, 1999.

This work was supported by Grants NS37423 and RR00165 from the National Institutes of Health. We thank Drs. Paul Bolam, Jeffrey Conn, Ali Charara, and Dieter Jaeger for comments and suggestions on this manuscript. Thanks also to Jean-François Paré for technical assistance and Frank Kiernan for photography.

Correspondence should be addressed to Dr. Yoland Smith, Yerkes Regional Primate Research Center, Emory University, 954, Gatewood Road NE, Atlanta, GA 30329.

Copyright (C) 1999 Society for Neuroscience 0270-6474/99/196488-09\$05.00/0
}

and cerebellum using pre- and post-embedding electron microscopic immunogold techniques (Baude et al., 1993; Nusser et al., 1994; Lujan et al., 1996; Ottersen and Landsend, 1997). These studies have demonstrated that group I mGluRs and ionotropic glutamate receptors are segregated within the postsynaptic membrane of asymmetric glutamatergic synapses (Nusser et al., 1994). Ionotropic receptors are found in the main body of the postsynaptic specializations, whereas group I mGluRs are preferentially expressed in a perisynaptic annulus around asymmetric synaptic junctions (Baude et al., 1993; Nusser et al., 1994; Lujan et al., 1996; Ottersen and Landsend, 1997).

The objective of the present study was to characterize the subsynaptic localization of group I mGluRs in the internal and external segments of the globus pallidus (GPi and GPe, respectively) in monkeys. Unlike dendrites of pyramidal cells in the hippocampus, which are covered with spines receiving asymmetric glutamatergic synapses, dendrites of GPe and GPi neurons are smooth and innervated predominantly by striatal GABAergic terminals, forming symmetric synapses intermingled with a small proportion of glutamatergic boutons, which, for the most part, arise from the subthalamic nucleus (Shink and Smith, 1995; Shink et al., 1996; Smith et al., 1998).

In this study, we present evidence that group I mGluRs in the monkey pallidum are found not only perisynaptic to asymmetric glutamatergic synapses but also in the main body of symmetric synaptic junctions established by striatal GABAergic terminals. These data raise questions about the possible sources of activation of these receptors and the potential roles of group I mGluRs in modulating neurotransmission at striatopallidal synapses.

\section{MATERIALS AND METHODS}

Animals and tissue processing. Four adult Rhesus monkeys (Macaca mulatta) were deeply anesthetized with an overdose of pentobarbital and perfused transcardially with cold oxygenated Ringer's solution followed by $4.0 \%$ paraformaldehyde and $0.1-1.0 \%$ glutaraldehyde in phosphate 
buffer (PB; $0.1 \mathrm{M}, \mathrm{pH} 7.4)$ at room temperature. Free aldehydes were washed out with PB. The brain was then removed from the skull, blocked, and post-fixed in the same fixative for $2 \mathrm{hr}$ at $4^{\circ} \mathrm{C}$ before being washed in PBS $(0.01 \mathrm{M}, \mathrm{pH} 7.4)$ and cut in $60-\mu \mathrm{m}$-thick transverse sections with a vibrating microtome. Sections were then treated with sodium borohydride (1.0\% in PBS) for $20 \mathrm{~min}$, rinsed in PBS, transferred to cryoprotectant, and frozen at $-80^{\circ} \mathrm{C}$ for $20 \mathrm{~min}$. They were then thawed and returned to a graded series of cryoprotectant and PBS.

Primary antisera. Two commercially available affinity-purified rabbit polyclonal antibodies raised against synthetic C-terminal peptides representing different amino acid sequences of mGluR1a (PNVTYASVILRDYKQSSSTL; Chemicon International, Temecula, CA) and mGluR5a and b (KSSPK YDTLIIRDYTNSSSSL; Upstate Biotechnology, Lake Placid, NY) were used in the present study. In immunoblot analysis of rat brain microsomes or rabbit brain extracts, both antibodies labeled a single band with an estimated molecular weight of $145 \mathrm{kDa}$, which corresponds to that of mGluR1a and mGluR5 proteins (Houamed et al., 1991; Abe et al., 1992; Minakami et al., 1993).

Light microscopic immunocytochemistry. The sections were preincubated for $1 \mathrm{hr}$ in $10 \%$ normal goat serum (NGS), 1.0\% bovine serum albumin (BSA), and $0.3 \%$ Triton X-100 in PBS before being incubated for $24 \mathrm{hr}$ at room temperature with primary antibodies (mGluR1a, 0.5 $\mu \mathrm{g} / \mathrm{ml}$; mGluR5, $1.0 \mu \mathrm{g} / \mathrm{ml})$ diluted in the antibody diluent $(1.0 \% \mathrm{NGS}$, $1.0 \%$ BSA, and $0.3 \%$ Triton X-100 in PBS). After rinsing with PBS, the sections were incubated for $1 \mathrm{hr}$ in biotinylated goat anti-rabbit IgGs (Vector Laboratories, Burlingame, CA) followed by avidin-biotin-peroxidase complex (ABC; Vector) diluted 1:200 in the antibody diluent. Sections were then washed in PBS and Tris buffer (0.05 M, pH 7.6) and transferred to a solution containing $0.025 \% 3,3^{\prime}$-diaminobenzidine tetrahydrochloride (Sigma, St Louis, MO), $0.01 \mathrm{~m}$ imidazole, and 0.005\% hydrogen peroxide for $10 \mathrm{~min}$. The sections were then washed in PBS, mounted on gelatin-coated slides, and dehydrated, and a coverslip was applied with Permount.

Electron microscopic immunocytochemistry. Sections prepared for electron microscopy were preincubated for $1 \mathrm{hr}$ with $10 \%$ NGS in a PBS-BSA solution $(0.05 \%$ Tween $20,0.005 \%$ BSA, and $0.001 \%$ gelatin in PBS) before being incubated for $48 \mathrm{hr}$ at $4^{\circ} \mathrm{C}$ in the same concentrations of anti-mGluR1a and -mGluR5 antibodies as used for light microscopy with $1.0 \% \mathrm{NGS} / \mathrm{PBS}-\mathrm{BSA}$ solution. The sections were then incubated for $2 \mathrm{hr}$ with the secondary antibody, $1.4 \mathrm{~nm}$ gold particle-conjugated goat antirabbit IgGs (Nanogold; Nanoprobes, Stonybrook, NY) diluted 1:100 in $1 \%$ NGS/PBS-BSA solution.

After overnight fixation in $1.0 \%$ glutaraldehyde, the sections were rinsed with $\mathrm{PB}$, and the gold particles were silver-intensified for 6-12 min with the HQ silver kit (Nanoprobes). They were then rinsed with PB, treated with osmium tetroxide $(1.0 \%$ in PB) for $20 \mathrm{~min}$, and dehydrated in a graded series of alcohol and propylene oxide. Uranyl acetate $(1.0 \%)$ was added to the $70 \%$ ethanol $(35 \mathrm{~min})$ to enhance contrast. Sections were embedded with epoxy resin (Durcupan, ACM; Fluka, Buchs, Switzerland) for $12 \mathrm{hr}$, mounted on microscope slides, and put in the oven at $60^{\circ} \mathrm{C}$ for $48 \mathrm{hr}$. Samples of GPe and GPi were then cut out from the slides, glued on the top of resin blocks with cyanoacrylate glue, and cut in 60to 70-nm-thick ultrathin sections with an ultramicrotome (Ultracut T2; Leica, Nussloch, Germany). The ultrathin sections were collected on single-slot copper or gold grids, stained with lead citrate (Reynolds, 1963) for $5 \mathrm{~min}$, and examined with a Zeiss EM-10C electron microscope (Thornwood, NY).

As controls, sections were incubated in solutions from which the primary antisera were replaced by $1 \%$ nonimmune rabbit serum, whereas the rest of the procedure remained the same as described above. Sections processed in this way were totally devoid of gold particles.

Analysis of material. To analyze the relationships between gold particles and postsynaptic specializations, micrographs of dendrites were taken at 25,000 and 40,000 $\times$ from the surface of mGluR1a- and mGluR5immunostained sections where the labeling was optimal. The gold particles attached to the plasma membrane were then counted and pooled into three categories (extrasynaptic, perisynaptic, and synaptic) based on their localization relative to postsynaptic membrane specializations visible in the plane of section (see Results for more details). Portions of dendrites in which the preservation or the plane of section was not suitable to distinguish the presynaptic and postsynaptic membranes were omitted from the analysis. To ascertain the specificity of labeling, immunoreactive synapses were examined in three to seven serial ultrathin sections.

For measurement of the surface of dendrites and length of synaptic junctions, micrographs of randomly selected immunolabeled dendrites taken from GPe and GPi were scanned with a digital scanner (Umax Powerlook II) and analyzed for total dendritic membrane length and total length of synaptic active zones using a Neurolucida setup and Morph software (MicroBrightField).

The mean size of gold particles was estimated by measuring the diameter of every gold particle attached to the plasma membrane in 10 dendrites in GPe and 10 dendrites in GPi for both receptor subtypes. Because there was no significant difference between the size of gold particles in the two pallidal segments with either antisera, data from GPe and GPi were pooled.

\section{RESULTS}

Group I mGluR immunoreactivity was examined at the light microscopic level using immunoperoxidase. Neuronal perikarya and dendritic processes displayed strong mGluR5 (Fig. 1A) and mGluR1a (Fig. 2A) immunoreactivity in both GPe and GPi. The pattern and intensity of staining for the two mGluR subtypes was the same throughout the entire extent of both pallidal segments. In general, the intensity of cytoplasmic labeling was stronger with the mGluR5 than the mGluR1a antibodies.

Because immunoperoxidase deposit is diff use and amorphous, it is not possible to establish the exact subcellular localization of receptors using that approach. Therefore, to elucidate the subsynaptic localization of mGluR1a and mGluR5 receptors at the electron microscopic level, both receptor subtypes were studied with the silver-intensified pre-embedding immunogold method, which offers a higher level of spatial resolution.

Overall, the pattern of distribution of the immunogold labeling in the four monkeys used in this study was consistent with the light microscopic peroxidase staining. First, the gold particles were associated exclusively with postsynaptic elements, including neuronal perikarya and dendritic processes of various sizes (Figs. $1 B, 2 C)$. Second, the density of gold particles in the cytoplasm of mGluR5-immunoreactive structures was significantly higher than that found in mGluR1a-containing elements, which is consistent with the relatively stronger mGluR5 cytoplasmic labeling visualized at the light microscopic level (Figs. $1 B, 2 C$ ). For studying the relationships between the group I mGluR subtype localization and synaptic junctions, immunoreactive dendrites were photographed in GPe and GPi of two monkeys with the best ultrastructural preservation. The gold particles attached to the plasma membrane were then counted and pooled into three categories based on their localization in relation to symmetric or asymmetric postsynaptic membrane specializations. Those gold particles that were bound to a part of the plasma membrane not contributing to synaptic junctions were categorized as "extrasynaptic," whereas gold particles that were found $<20 \mathrm{~nm}$ away from the edge of symmetric or asymmetric postsynaptic membrane specializations were categorized as "perisynaptic." Finally, gold particles that were bound to the main body of the postsynaptic specialization of symmetric or asymmetric synapses were categorized as "synaptic."

The distribution of membrane-bound immunogold particles observed for mGluR1a and mGluR5 labeling in the two segments of the globus pallidus is shown in Figure $3 A$. No substantial difference in the subsynaptic distribution of mGluR1a and mGluR5 immunoreactivity was found between the two pallidal segments. Although the majority of gold particles were extrasynaptic, a substantial proportion of immunolabeling (27-44\% gold particles) was also found to be associated with symmetric synapses established by terminals that displayed the ultrastructural features of striatal boutons in GPe and GPi (Figs. $1 B, F-H, 2 B, C$, $3 A$ ). Moreover, quantitative measurements revealed that $80-90 \%$ 


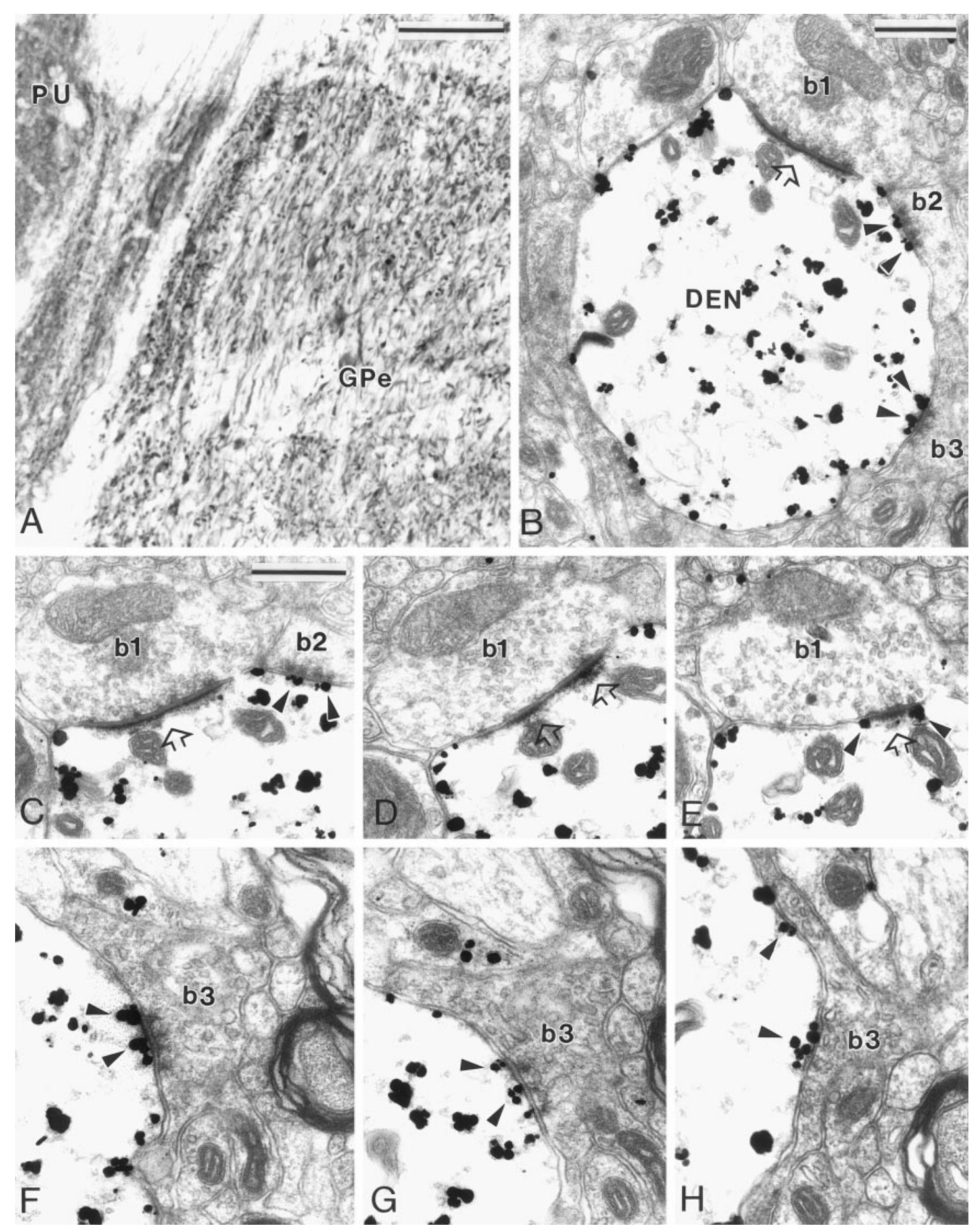

Figure 1. MGluR5 immunolabeling in GPe. $A$, Light microscopic immunoperoxidase mGluR5 labeling in GPe and putamen (PU). B, Electron micrograph of an mGluR5-positive dendrite (DEN) contacted by three boutons that display clear synaptic specializations (b1-b3). Bouton $b 1$, which displays the ultrastructural features of a subthalamic terminal, forms an asymmetric synapse (open arrow), whereas b2 and b3, which are typical striatal boutons, form symmetric synaptic contacts. Note the gold particles located in the postsynaptic specializations of the symmetric synapses established by $b 2$ and $b 3$ (arrowheads). $C-E$, Serial ultrathin sections of $b 1$ showing the perisynaptic mGluR5 labeling (E, arrowheads) at the asymmetric synapse (open arrows). In $C$, the arrowheads point out gold particles located at the symmetric synaptic junction established by striatal-like bouton $b 2$. $F-H$, Electron micrographs showing serial sections of mGluR5 labeling (arrowheads) at the postsynaptic specialization of the symmetric synapse established by $b 3$. Note that the gold particles are found in the main body of the symmetric postsynaptic specialization in the three serial sections. Scale bars: $A, 100 \mu$ m; $B, C$, $0.5 \mu \mathrm{m}$ (valid for $D-H$ ).

of those gold particles associated with symmetric synapses were found in the main body of the postsynaptic specialization (Figs. $1 B, C, F-H, 2 B, C, 3 B)$. In contrast, immunogold particles associated with asymmetric synapses established by subthalamic-like terminals were always found in a perisynaptic position at the edges of synaptic junctions (Fig. $1 C-E$ ).

To make sure that the labeling at symmetric synapses was not merely an artifact of a random distribution of gold particles along 


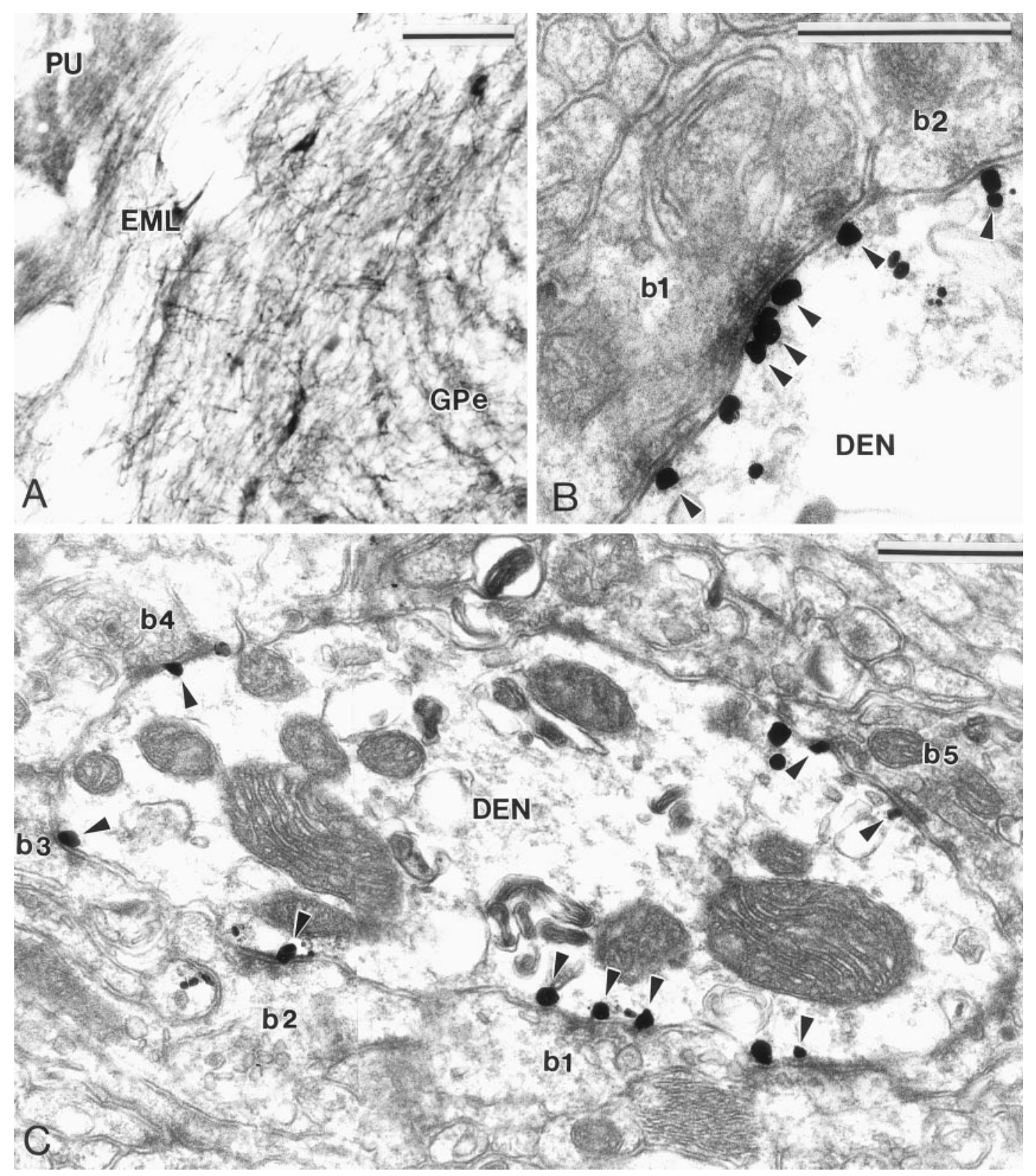

Figure 2. Group I mGluR immunolabeling in GPe and GPi. $A$, Light microscopic immunoperoxidase mGluR1a labeling in GPe and putamen (PU). Note that large neurons in the external medullary lamina $(E M L)$, which likely correspond to the cholinergic neurons of the basal nucleus of Meynert, also display strong mGluR1a immunoreactivity. $B$, Electron micrograph of mGluR5 immunolabeling at symmetric axodendritic synapses established by two striatal-like terminals $(b 1, b 2)$. Note that gold particles aggregate in the main body of postsynaptic specializations (arrowheads). $C$, mGluR1aimmunoreactive dendrite $(D E N)$ contacted by numerous striatal-like terminals (b1-b5). Most of the gold particles (arrowheads) are specifically located at the postsynaptic specialization of symmetric striatopallidal synapses. Scale bars: $A, 100 \mu \mathrm{m} ; B, C, 0.5 \mu \mathrm{m}$.

the plasma membrane of pallidal neurons, we performed two additional series of observations. First, we examined immunoreactive synapses through serial sections and found that the synaptic labeling at individual immunoreactive striatopallidal synapses was maintained in three to seven serial sections (Fig. $1 F-H$ ). Furthermore, that the silver-enhanced gold particles had a mean diameter of $37.6 \pm 13.4 \mathrm{~nm}$ (Mean $\pm \mathrm{SD} ; n=125)$ indicates that an individual particle could not be found in more than two adjacent ultrathin (60- to 70-nm-thick) sections. Therefore, because some symmetric synapses were labeled in as many as seven serial sections, this means that multiple gold particles contributed to the immunostaining. Second, the predicted percentage of gold particles found at synapses based on a random distribution on the dendritic membrane was calculated. This was achieved by comparing the proportion of the surface of dendritic membranes involved in the formation of symmetric or asymmetric synapses with the percentages of gold particles associated with striatal and subthalamic-like synapses (Fig. 3A). A randomly selected sample of 20 dendrites in GPe and 20 dendrites in GPi were photographed and measured. In total, these dendrites accounted for $\sim 2$ $\mathrm{mm}$ of dendritic membrane from which data were collected. Because no significant difference was found between GPe and $\mathrm{GPi}$, the percentages of dendritic membrane involved in synaptic specializations in both pallidal segments were pooled (Fig. 4). 
A

Figure 3. Subsynaptic distribution of group I mGluRs in GPe and GPi. $A$, Histogram showing the relative distribution of membrane-bound gold particle labeling for mGluR1a and mGluR5 on GPi and GPe dendrites. The total number of gold particles for each category is indicated in parentheses. A total of 125 dendrites in each pallidal segment were examined in mGluR1a- and mGluR5-immunostained sections. No gold labeling was found in the main body of the postsynaptic specializations of asymmetric synapses. $B$, Histogram showing the relative distribution of synaptic versus perisynaptic group I mGluRs labeling at symmetric striatopallidal synapses. For each category, the number of gold particles associated with symmetric synapses is given in parentheses.
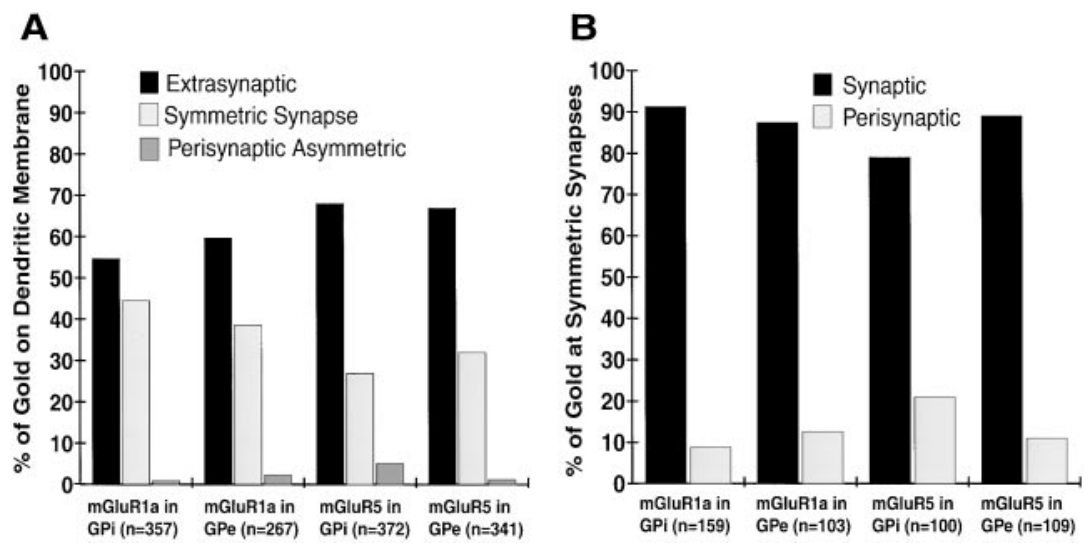

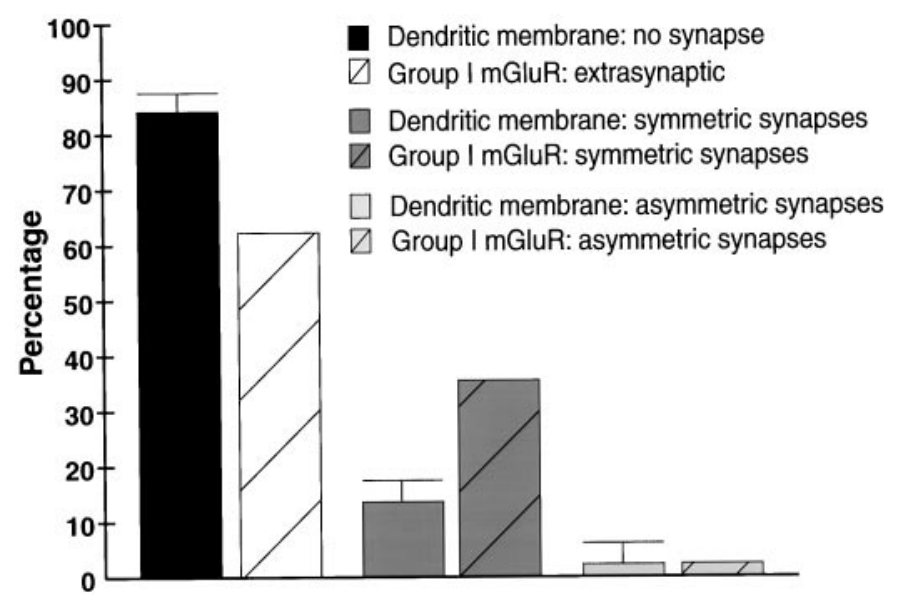

Figure 4. Histogram comparing the percentage (Mean $\pm \mathrm{SD}$ ) of dendritic membrane of GPe and GPi neurons not contributing to any synaptic junctions (no synapse) or involved in the formation of symmetric and asymmetric synapses, with the percentages of membrane-bound gold particle labeling for group I mGluRs on pallidal dendrites. The total membrane length and total length of symmetric and asymmetric synaptic active zones were measured from 40 dendrites randomly selected in GPe and GPi. The percentages of membrane-bound gold particles associated with group I mGluR immunoreactivity are the averages of mGluR1a and mGluR5 labeling in GPe and GPi depicted in Figure $3 A$. Note that the percentage of dendritic membrane contributing to the formation of symmetric synapses is significantly lower than the proportion of group I mGluR immunogold labeling at striatopallidal synapses.

These measurements revealed that $\sim 85 \%$ of the membrane of pallidal dendrites does not contribute to synaptic specializations, whereas $\sim 13 \%$ contribute to symmetric synapses, and $\sim 2 \%$ contribute to asymmetric synapses (Fig. 4). Thus, on the basis of a random distribution, a substantially lower percentage of gold particle labeling would be predicted at symmetric striatopallidal synapses than was found for group I mGluR labeling in both pallidal segments (Fig. 4).

Because most of the previous findings on the synaptic localization of group I mGluRs were gained from the rat hippocampus with antibodies different from those used in the present study (Baude et al., 1993; Lujan et al., 1996), we examined the distribution of mGluR5 labeling in the CA1 region of the hippocampus in two monkeys and confirmed that (1) immunogold particles were always found outside asymmetric postsynaptic specializations (Fig. $5 A$ ); (2) spines were the most intensely labeled elements; (3) a substantial percentage $(33 \%)$ of gold particles were found to be perisynaptic to asymmetric axospinous and axoden- dritic synapses, whereas the remainder $(67 \%)$ were found to be extrasynaptic (Fig. 5C); and (4) no labeling was found at symmetric synapses (Fig. $5 B$ ). These observations indicate that our findings in the monkey pallidum are unlikely to be attributable to either differences in the specificity of antibodies used in these studies or an overall species difference between rodents and primates regarding the subsynaptic localization of group I mGluRs in the CNS.

\section{DISCUSSION}

The main finding of this study is that group I mGluRs are found not only perisynaptic to the postsynaptic densities of asymmetric synapses but also in the core of the postsynaptic membrane specializations of symmetric striatopallidal synapses in monkeys (Fig. 6). These data raise questions about the possible sources of activation of these receptors and the potential roles of group I mGluRs in modulating neurotransmission at GABAergic striatopallidal synapses.

As discussed above, the current view of the subsynaptic distribution of group I mGluRs in the CNS is largely based on data obtained in the hippocampus and the cerebellum in rats (Nusser et al., 1994; Lujan et al., 1996; Ottersen and Landsend, 1997). In those two brain regions, where neurons receive massive glutamatergic inputs, group I mGluRs were found to be perisynaptic to glutamatergic synapses. Our findings confirm that such is also the case in the monkey pallidum, where gold particle labeling for mGluR1a and mGluR5 was frequently found at the edges of asymmetric postsynaptic specializations. Gold particles were never found in the main body of asymmetric synapses in the pallidum, the striatum, the subthalamic nucleus, or the substantia nigra pars reticulata in monkeys (Hubert et al., 1998; Hubert and Smith, 1999; Paquet et al., 1999). Although this lack of immunoreactivity in the core of asymmetric synapses might arise from problems of antibody access to epitopes, various observations suggest that such is unlikely to be the case for group I mGluRs: (1) the perisynaptic localization of these receptors was found in many brain regions using different antibodies in both rats and monkeys (Nusser et al., 1994; Lujan et al., 1996; Hubert and Smith, 1999; Paquet et al., 1999); (2) in the rat hippocampus, the perisynaptic labeling was found using both pre- and postembedding immunogold methods (Lujan et al., 1996); and (3) the main body of asymmetric postsynaptic specializations was found to be strongly labeled with various ionotropic glutamate receptor subunit antibodies (Nusser et al., 1994, 1998; Bernard et al., 1997; Clarke and Bolam, 1998). Together, these findings strongly suggest that the perisynaptic localization of group I mGluRs at 

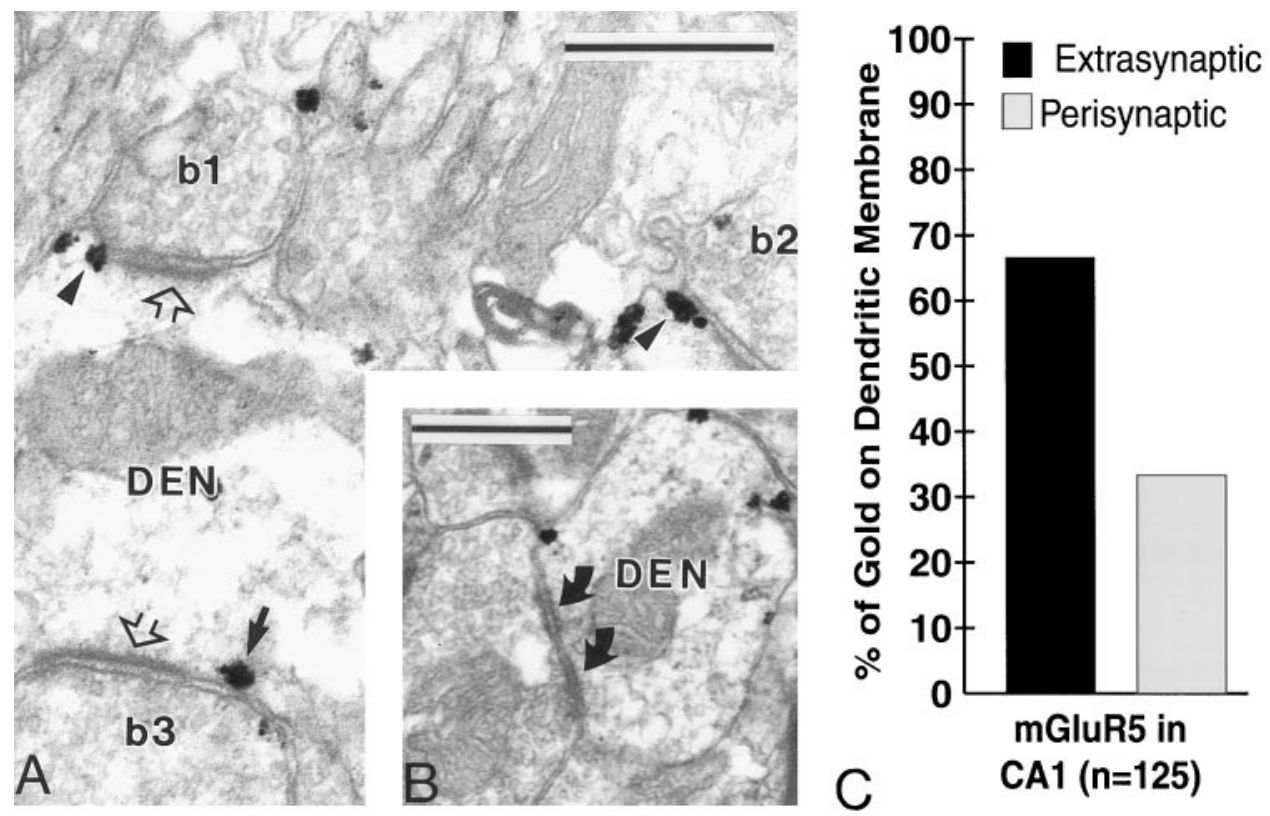

Figure 5. Immunogold dendritic labeling for mGluR5 in the CA1 region of the monkey hippocampus. $A$, Electron micrograph of three boutons (b1-b3) forming asymmetric axodendritic synapses (open arrows). Note the perisynaptic mGluR5 immunostaining (arrowheads) at the synapses established by $b 1$ and $b 2$. The arrow indicates a gold particle considered extrasynaptic according to our criteria, because it is found $>20 \mathrm{~nm}$ away from the edge of the asymmetric postsynaptic specialization. $B$, Electron micrograph showing a symmetric axodendritic synapse (curved arrows) devoid of mGluR5 immunoreactivity. DEN, Dendrite. $C$, Histogram showing the percentage of extrasynaptic versus perisynaptic mGluR5 labeling on the surface of dendrites in the hippocampus. The perisynaptic labeling was always associated with asymmetric synapses. No labeling was found at symmetric synapses in the hippocampus. The total number of membrane-bound gold particles examined in 60 dendrites is given in parentheses. Scale bar, $0.5 \mu \mathrm{m}$.

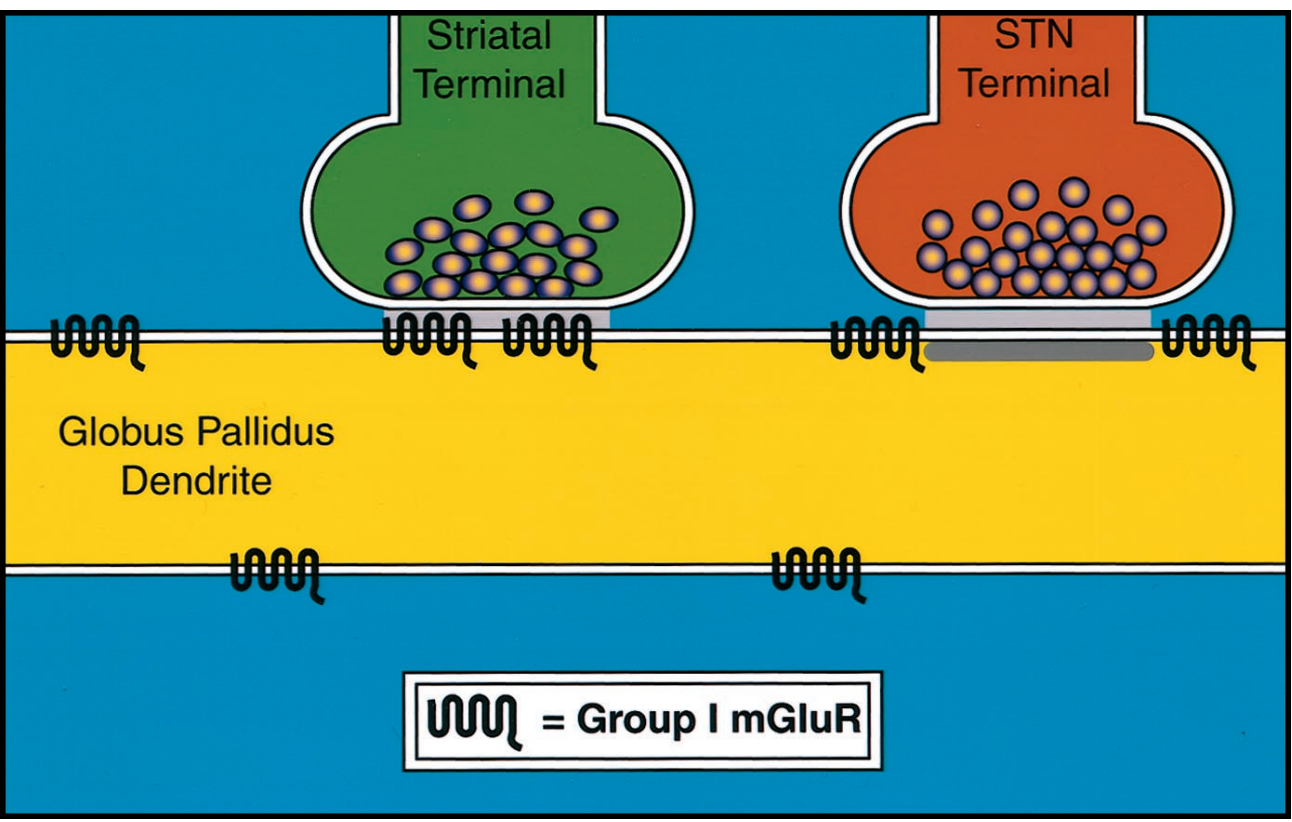

Figure 6. Schematic diagram that summarizes the subsynaptic localization of group I mGluRs in the GPi and GPe in monkeys. Both mGluR1a and mGluR5 are found in the main body of postsynaptic specializations of symmetric striatopallidal synapses or at the edges of asymmetric synapses established by subthalamic-like terminals. A large proportion of group I mGluRs are also found extrasynaptically on parts of pallidal dendrites not contributing to any synaptic junctions.

excitatory synapses is unlikely to be the result of technical artifacts but rather represents a genuine phenomenon in the CNS of both primates and nonprimates.

One of the unexpected findings of this study is the localization of group I mGluRs in the main body of the postsynaptic membrane specialization of symmetric synapses established by striatal terminals. Although the transmitter content of striatal terminals presynaptic to group I mGluR immunoreactivity has not been characterized in the present study, the ultrastructural features and GABA immunoreactivity of these terminals has been the subject of extensive studies during the past 10 years in rats and monkeys (for review, see Smith et al., 1998). Therefore, that striatal neurons use GABA as a neurotransmitter raises important questions about the functional role of mGluRs at these synapses. One could argue that this labeling was either nonspecific or coincidental, because the surface of pallidal dendrites is covered with striatal boutons. However, different sets of data rule out these possibilities. First, the two polyclonal antibodies used in this study were affinity-purified and found to be highly specific for their immunogen in Western Immunoblot analysis. Second, omission of the antibodies completely abolished the immunostaining. Third, the pattern of labeling observed in the monkey hippocampus with the mGluR5 antibodies was strikingly similar to that recently described in rats using another highly specific mGluR5 antiserum raised against a different epitope (Shigemoto et al., 1993; Lujan et al., 1996). Fourth, the labeling at individual symmetric striatopallidal synapses was found in three to seven serial sections. Fifth, the total proportion of the surface of pallidal dendrites involved in the formation of symmetric synapses was much lower than the proportion of gold particles encountered at symmetric striatopallidal synapses in GPe and GPi.

Another concern could be that the labeling at symmetric syn- 
apses was attributable to cross-reaction of our antibodies with the GABAB receptors. This is very unlikely, because the synthetic peptides used to generate the mGluR1a and mGluR5 antibodies do not have any significant homologies with the amino acid sequence of the GABAB-R1 and GABAB-R2 receptor subtypes (Kaupmann et al., 1997, 1998; White et al., 1998). Moreover, recent electron microscopic localization studies of GABAB-R1 immunoreactivity in the monkey basal ganglia revealed a pattern of labeling significantly different from that described in the present study for group I mGluRs (Charara et al., 1999). Thus, these findings indicate that the mGluR labeling at symmetric synapses in the monkey pallidum is highly specific, which suggests a potential role for group I mGluRs in modulating GABAergic transmission at striatopallidal synapses. This apparent mismatch between receptor localization and neurotransmitter release is not unique to group I mGluRs. Nusser et al. (1998) found similar findings in the rat cerebellum, where they showed that the $\gamma 2, \alpha 6$, and $\beta 2 / 3$ GABA-A receptor subunits coexist with AMPA receptors in some glutamatergic mossy fiber synapses.

It is worth noting that the postsynaptic specializations of symmetric synapses were not labeled in the CA1 region of the hippocampus in rats (Lujan et al., 1996) and monkeys. Whether this represents a genuine difference in group I mGluR localization at GABAergic synapses between the hippocampus and the pallidum or results from a more limited access to antigenic sites at symmetric synapses in the hippocampus remains uncertain.

The main issue that remains to be established is the mechanism by which these receptors are activated and mediate their effects. One possibility is that glutamate released from astrocytes activates mGluRs located at symmetric synapses and, possibly, those located extrasynaptically. Data obtained during the past few years showing that astrocytes express various ion channels and contain glutamate receptors (Sontheimer et al., 1996; Steinhauser and Gallo, 1996; Verkhratsky and Kettenmann, 1996; Porter and McCarthy, 1997; Carmignoto et al., 1998) have shifted the traditional concept of astrocytes as simple structural support for neurons to a view in which glial cells play a more active role in information processing and neuronal communication in the CNS (Parpura et al., 1994; Antanitus, 1998; Araque et al., 1999). It is well established that neuronal stimulation induces waves of elevated intracellular calcium, which propagate between glial cells and lead to glutamate release (Parpura et al., 1994; Hassinger et al., 1995; Araque et al., 1998a,b). Moreover, electrical or mechanical stimulation of astrocytes can evoke NMDA and non-NMDA receptor-dependent slow inward currents in cultured hippocampal neurons (Araque et al., 1998b). Calcium elevation in astrocytes also increases the frequency of excitatory miniature postsynaptic currents by acting on extrasynaptic NMDA receptors in those neurons (Araque et al., 1998b). Finally, astrocytes can modulate action potential-evoked synaptic transmission by activation of presynaptic mGluRs (Araque et al., 1998a). Thus, even if in vivo glutamate release from astrocytes has not been demonstrated in the globus pallidus, the findings discussed above suggest that glia should definitely be considered a potential candidate while looking for a source of glutamate to activate mGluRs expressed at GABAergic synapses or extrasynaptically in the monkey pallidum.

Another possibility is that glutamate released from subthalamic terminals diff uses out of the synaptic cleft and activates receptors located extrasynaptically or at symmetric synapses on pallidal dendrites. It has, indeed, been found that glutamate can spill over from neighboring synapses and can activate ionotropic glutamate receptors in the hippocampus (Asztely et al., 1997; Barbour and Hausser, 1997; Kullmann and Asztely, 1998; Kullmann et al., 1999). Although such might also be the case in the pallidum, the fact that the labeled striatopallidal synapses were not always adjacent to asymmetric synapses makes the "spillover" hypothesis less likely to account for activation of most of these receptors. However, glutamate transporters are known to play a critical role in limiting the extrasynaptic diffusion of glutamate, thereby minimizing cross-talk between neighboring synapses (Rothstein et al., 1996; Diamond and Jahr, 1997; Rusakov and Kullmann, 1998). One possibility could be that subthalamopallidal synapses are devoid of glutamate transporters, which would allow the transmitter to reach locations relatively distant from the site of release and to activate group I mGluRs. Studies of glutamate transporter location and abundance in the primate pallidum are in progress to assess the possible role of glutamate diffusion in activating group I mGluRs.

A third possibility is that striatal terminals, under certain circumstances, release excitatory amino acids. Although this is not consistent with the current view of neurotransmission at striatopallidal synapses, indirect evidence suggests that striatal neurons may coexpress, and possibly corelease, GABA and glutamate as neurotransmitters. First, striatopallidal neurons possess a high-affinity uptake system for glutamate and aspartate (White et al., 1994). Second, excitatory postsynaptic currents sensitive to the glutamate antagonist CNQX are found in cultures consisting only of dissociated striatal neurons (Dubinsky, 1989). Third, stimulation of the caudate nucleus in vivo produces a combination of excitatory and inhibitory postsynaptic potentials in the globus pallidus (Levine et al., 1974; Kita and Kitai, 1991). Although these excitatory effects can be attributed to activation of axons extrinsic to the striatum or multisynaptic pathways, they might also originate from intrinsic striatal neurons. Taken together with the findings of the present study, these data support the idea that glutamate might be released by either GABAergic striatal projection neurons in general or a subpopulation of neurons specifically associated with synaptic group I mGluRs. Because of limitations in interpreting negative immunocytochemical staining, the exact proportion of striatal synapses associated with group I mGluRs could not be established in the present study. Although corelease of fast neurotransmitters such as glutamate and GABA is clearly not a common feature in the CNS, the synaptic corelease of GABA and glycine was recently shown in the spinal cord (Jonas et al., 1998). Furthermore, Jo and Schlichter (1999) recently demonstrated that the fast excitatory neurotransmitter ATP is coreleased with the inhibitory neurotransmitter GABA at individual synapses in cultured spinal neurons.

If glutamate, indeed, activates mGluRs at striatopallidal synapses, it is likely that the postsynaptic mGluR responses regulate GABA currents in pallidal neurons. Although the mechanism of such an interaction between GABA receptors and mGluRs is largely unknown, recent data indicate that mGluR activation might either downregulate or upregulate inhibitory postsynaptic currents in the nucleus of the solitary tract and the spinal cord in rats (Glaum and Miller, 1993, 1994). Furthermore, activation of group I mGluRs was found to depress GABA-A-mediated IPSCs in slices of rat midbrain dopaminergic neurons (Bonci et al., 1997). Similar findings were found in the hippocampus, where activation of group I mGluRs also mimicked and occluded the phenomenon of depolarization-induced suppression of inhibition (Morishita et al., 1998). Finally, mGluR activation can modulate postsynaptic GABA responses via the reduction of $\mathrm{K}^{+}$conduc- 
tances, which leads to an increase in membrane excitability and depression of GABA receptor sensitivity (Glaum and Miller, 1994; Conn and Pin, 1997).

It is worth noting that group I mGluR activation has been shown to mediate both slow IPSPs and EPSPs in midbrain dopamine neurons (Fiorillo and Williams, 1998). Activation of mGluR1 by a brief exposure to agonist was found, indeed, to activate a $\mathrm{Ca}^{2+}$-dependent potassium conductance and to cause a pure inhibition, whereas prolonged exposure to agonist resulted in suppression of the IPSPs and evoked a slow EPSP (Fiorillo and Williams, 1998). Thus, while looking for a functional role for group I mGluRs in the pallidum, it is important to consider that these receptors could have effects ranging from increasing excitability to causing inhibition.

\section{REFERENCES}

Abe T, Sugihara H, Nawa H, Shigemoto R, Mizuno N, Nakanishi S (1992) Molecular characterization of a novel metabotropic glutamate receptor mGluR5 coupled to inositol phosphate $/ \mathrm{Ca}^{2+}$ signal transduction. J Biol Chem 267:13361-13368.

Antanitus DS (1998) A theory of cortical neuron-astrocyte interaction. Neuroscientist 4:154-159.

Araque A, Parpura V, Sanzgiri RP, Haydon PG (1998a) Glutamatedependent astrocyte modulation of synaptic transmission between cultured hippocampal neurons. Eur J Neurosci 10:2129-2142.

Araque A, Sanzgiri RP, Parpura V, Haydon PG (1998b) Calcium elevation in astrocytes causes an NMDA receptor-dependent increase in the frequency of miniature synaptic currents in cultured hippocampal neurons. J Neurosci 18:6822-6829.

Araque A, Parpura V, Sanzgiri R, Haydon PG (1999) Tripartite synapses: glia, the unacknowledged partner. Trends Neurosci 22:208-215.

Asztely F, Erdemli G, Kullmann DM (1997) Extrasynaptic glutamate spillover in the hippocampus: dependence on temperature and the role of active glutamate uptake. Neuron 18:281-293.

Barbour B, Hausser M (1997) Intersynaptic diffusion of neurotransmitter. Trends Neurosci 20:377-384.

Baude A, Nusser Z, Roberts JD, Mulvihill E, McIlhinney RA, Somogyi $\mathrm{P}$ (1993) The metabotropic glutamate receptor (mGluR1 $\alpha$ ) is concentrated at perisynaptic membrane of neuronal subpopulations as detected by immunogold reaction. Neuron 11:771-787.

Bernard V, Somogyi P, Bolam JP (1997) Cellular, subcellular, and subsynaptic distribution of AMPA-type glutamate receptor subunits in the neostriatum of the rat. J Neurosci 17:819-883.

Berthele A, Laurie DJ, Platzer S, Zieglgansberger W, Tolle TR, Sommer B (1998) Differential expression of rat and human type I metabotropic glutamate receptor splice variant messenger RNAs. Neuroscience 85:733-749.

Bonci A, Grillner P, Siniscalchi A, Mercuri NB, Bernardi G (1997) Glutamate metabotropic receptor agonists depress excitatory and inhibitory transmission on rat mesencephalic principal neurons. Eur J Neurosci 9:2359-2369.

Carmignoto G, Pasti L, Pozzan T (1998) On the role of voltagedependent calcium channels in calcium signaling of astrocytes in situ. J Neurosci 18:4637-4645.

Charara A, Heilman C, Levey AI, Smith Y (1999) Cellular and subcellular localization of $\mathrm{GABA}_{\mathrm{B}}$ receptors in the basal ganglia in monkeys. Soc Neurosci Abstr, in press.

Clarke NP, Bolam JP (1998) Distribution of glutamate receptor subunits at neurochemically characterized synapses in the entopeduncular nucleus and subthalamic nucelus of the rat. J Comp Neurol 397:403-420.

Conn PJ, Pin JP (1997) Pharmacology and functions of metabotropic glutamate receptors. Annu Rev Pharmacol Toxicol 37:205-237.

Diamond JS, Jahr CE (1997) Transporters buffer synaptically released glutamate on a submillisecond time scale. J Neurosci 17:4672-4687.

Dubinsky JM (1989) Development of inhibitory synapses among striatal neurons in vitro. J Neurosci 9:3955-3965.

Fiorillo CD, Williams JT (1998) Glutamate mediates an inhibitory postsynaptic potential in dopamine neurons. Nature 394:78-82.

Glaum SR, Miller RJ (1993) Activation of metabotropic glutamate receptors produces reciprocal regulation of ionotropic glutamate and
GABA responses in the nucleus of the tractus solitarius of the rat. J Neurosci 13:1636-1641.

Glaum SR, Miller RJ (1994) Acute regulation of synaptic transmission by metabotropic glutamate receptors. In: The metabotropic glutamate receptors (Conn PJ, Patel J, eds), pp 147-172. Totowa, NJ: Humana.

Hassinger TD, Atkinson PB, Strecker GJ, Whalen LR, Dudek FE, Kossel AH, Kater SB (1995) Evidence for glutamate-mediated activation of hippocampal neurons by glial calcium waves. J Neurobiol 28:159-170.

Houamed KM, Kuijper JL, Gilbert TL, Haldeman BA, O'Hara PJ, Mulvihill ER, Almers W, Hagen FS (1991) Cloning, expression and gene structure of a G-protein-coupled glutamate receptor from rat brain. Science 252:1318-1321.

Hubert GW, Smith Y (1999) Subsynaptic localization of group I metabotropic glutamate receptors (mGluRs) in the ventral midbrain of rats. Soc Neurosci Abstr, in press.

Hubert GW, Paré J-F, Robida AM, Bradley SR, Levey AI, Conn PJ, Smith Y (1998) Subsynaptic localization of metabotropic glutamate receptors (mGluRs) in the globus pallidus and subthalamic nucleus in monkeys. Soc Neurosci Abstr 24:1650.

Jo Y-H, Schlichter R (1999) Synaptic corelease of ATP and GABA in cultured spinal neurons. Nat Neurosci 2:241-245.

Jonas P, Bischofberger J, Sandkuhler J (1998) Corelease of two fast neurotransmitters at a central synapse. Science 281:419-424.

Kaupmann K, Huggel K, Heid J, Flor PJ, Bischoff S, Mickel SJ, McMaster G, Angst C, Bittiger H, Froestl W, Bettler B (1997) Expression cloning of $\mathrm{GABA}_{\mathrm{B}}$ receptors uncovers similarity to metabotropic glutamate receptors. Nature 386:239-246.

Kaupmann K, Malitschek B, Schuler V, Froestl W, Beck P, Mosbacher J, Bischoff S, Kulik A, Shigemoto R, Karschin A, Bettler B (1998) $\mathrm{GABA}_{\mathrm{B}}$-receptor subtypes assemble into functional heteromeric complexes. Nature 396:683-687.

Kita H, Kitai ST (1991) Intracellular study of rat globus pallidus neurons: membrane properties and responses to neostriatal, subthalamic and nigral stimulation. Brain Res 564:296-305.

Kullmann DM, Asztely F (1998) Extrasynaptic glutamate spillover in the hippocampus: evidence and implications. Trends Neurosci 21:8-14.

Kullmann DM, Min M-Y, Asztely F, Rusakov DA (1999) Extracellular glutamate diff usion determines the occupancy of glutamate receptors at CA1 synapses in the hippocampus. Philos Trans R Soc Lond B Biol Sci 354:395-402.

Levine MS, Hull CD, Buchwald NA (1974) Pallidal and entopeduncular intracellular responses to striatal, cortical, thalamic, and sensory inputs. Exp Neurol 44:448-460.

Lujan R, Nusser Z, Roberts JD, Shigemoto R, Somogyi P (1996) Perisynaptic location of metabotropic glutamate receptors mGluR1 and mGluR5 on dendrites and dendritic spines in the rat hippocampus. Eur J Neurosci 8:1488-1500.

Martin LJ, Blackstone CD, Huganir RL, Price DL (1992) Cellular localization of a metabotropic glutamate receptor in rat brain. Neuron 9:259-270.

Minakami R, Katsuki F, Sugiyama H (1993) A variant of metabotropic glutamate receptor subtype 5: an evolutionally conserved insertion with no termination codon. Biochem Biophys Res Commun 194:622-627.

Morishita W, Kirov SA, Alger BE (1998) Evidence for metabotropic glutamate receptor activation in the induction of depolarizationinduced suppression of inhibition in hippocampal CA1. J Neurosci 18:4870-4882.

Nakanishi S (1994) Metabotropic glutamate receptors: synaptic transmission, modulation, and plasticity. Neuron 13:1031-1037.

Nusser Z, Mulvihill E, Streit P, Somogyi P (1994) Subsynaptic segregation of metabotropic and ionotropic glutamate receptors as revealed by immunogold localization. Neuroscience 61:421-427.

Nusser Z, Sieghart W, Somogyi P (1998) Segregation of different $\mathrm{GABA}_{\mathrm{A}}$ receptors to synaptic and extrasynaptic membranes of cerebellar granule cells. J Neurosci 18:1693-1703.

Ottersen OP, Landsend AS (1997) Organization of glutamate receptors at the synapse. Eur J Neurosci 9:2219-2224.

Paquet M, Bradley SR, Conn PJ, Smith Y (1999) Subcellular and subsynaptic distribution of metabotropic glutamate receptors in the monkey striatum. Soc Neurosci Abstr, in press.

Parpura V, Basarsky TA, Liu F, Jeftinija S, Haydon PG (1994) Glutamate-mediated astrocyte-neuron signaling. Nature 369:744-747.

Petralia RS, Wang YX, Singh S, Wu C, Shi L, Wei J, Wenthold RJ (1997) A monoclonal antibody shows discrete cellular and subcellular local- 
izations of mGluR1 $\alpha$ metabotropic glutamate receptors. J Chem Neuroanat 13:77-93.

Pin JP, Duvoisin R (1995) The metabotropic glutamate receptors: structure and functions. Neuropharmacology 34:1-26.

Porter JT, McCarthy KD (1997) Astrocytic neurotransmitter receptors in situ and in vivo. Prog Neurobiol 51:439-455.

Reynolds ES (1963) The use of lead citrate at high $\mathrm{pH}$ as an electron opaque stain in electron microscopy. J Cell Biol 17:208-212.

Rothstein JD, Dykes-Hoberg M, Pardo CA, Bristol LA, Jin L, Kuncl RW, Kanai Y, Hediger MA, Wang Y, Schielke JP, Welty DF (1996) Knockout of glutamate transporters reveals a major role for astroglial transport in excitotoxicity and clearance of glutamate. Neuron 16:675-686.

Rusakov DA, Kullmann DM (1998) Extrasynaptic glutamate diffusion in the hippocampus: ultrastructural constraints, uptake, and receptor activation. J Neurosci 18:3158-3170.

Shigemoto R, Nomura S, Ohishi H, Sugihara H, Nakanishi S, Mizuno N (1993) Immunohistochemical localization of a metabotropic glutamate receptor, mGluR5, in the rat brain. Neurosci Lett 163:53-57.

Shink E, Smith Y (1995) Differential synaptic innervation of neurons in the internal and external segments of the globus pallidus by the GABAand glutamate-containing terminals in the squirrel monkey. J Comp Neurol 358:119-141.

Shink E, Bevan MD, Bolam JP, Smith Y (1996) The subthalamic nucleus and the external pallidum: two tightly interconnected structures that control the output of the basal ganglia in the monkey. Neuroscience 73:335-357.

Smith Y, Shink E, Bevan MD, Bolam JP (1998) Synaptology of the direct and indirect striatof ugal pathways. Neuroscience 86:353-387.

Sontheimer H, Black JA, Waxman SG (1996) Voltage-gated $\mathrm{Na}^{+}$channels in glia: properties and possible functions. Trends Neurosci 19:325-331.

Steinhauser C, Gallo V (1996) News on glutamate receptors in glial cells. Trends Neurosci 19:339-345.

Testa CM, Standaert DG, Young AB, Penney Jr JB (1994) Metabotropic glutamate receptor mRNA expression in the basal ganglia of the rat. J Neurosci 14:3005-3018.

Testa CM, Friberg IK, Weiss SW, Standaert DG (1998) Immunohistochemical localization of metabotropic glutamate receptors mGluR1a and mGluR2/3 in the rat basal ganglia. J Comp Neurol 390:5-19.

Verkhratsky A, Kettenmann H (1996) Calcium signalling in glial cells. Trends Neurosci 19:346-351.

White LE, Hodges HD, Carnes KM, Price JL, Dubinsky JM (1994) Colocalization of excitatory and inhibitory neurotransmitter markers in striatal projection neurons in the rat. J Comp Neurol 339:328-340.

White JH, Wise A, Main MJ, Green A, Fraser NJ, Disney GH, Barnes AA, Emson P, Foord SM, Marshall FH (1998) Heterodimerization is required for the formation of a functional $\mathrm{GABA}_{\mathrm{B}}$ receptor. Nature 396:679-682. 